\title{
Knowledge of Biosafety Measures among Laboratory Personnel at Tertiary Level Public Hospitals in Dhaka City
}

\author{
Md. Nowfel Islam¹, Md. Humayun Kabir², Md. Abdullah Yusuf ${ }^{3}$, Md. Badius Salam4, \\ Irin Perveen ${ }^{5}$, Sadia Shirin ${ }^{6}$
}

${ }^{1}$ Professor and Head, Department of Neuropathology, National Institute of Neurosciences \& Hospital, Dhaka, Bangladesh; ${ }^{2}$ Joint Secretary, Additional Director General, Department of Environment, Bangladesh Secretariat, Dhaka, Bangladesh; ${ }^{3}$ Assistant Professor, Department of Microbiology, National Institute of Neurosciences \& Hospital, Dhaka, Bangladesh; ${ }^{4}$ Assistant Professor \& Head, Department of Radiation Oncology, Sir Salimullah Medical College, Dhaka, Bangladesh; ${ }^{5}$ Professor \& Head, Department of Gastroenterology, Enam Medical College, Dhaka, Bangladesh; ${ }^{6}$ Medical Officer, Department of Neuropathology, National Institute of Neurosciences \& Hospital, Dhaka, Bangladesh

[Received: 12 July 2020; Accepted: 30 August 2020; Published: 1 December 2020]

\begin{abstract}
Background: Biosafety is the principles, technologies and practices that are implemented to prevent the unintentional exposure to pathogens and toxins. Objective: The purpose of the present study was to assess the Status of biosafety safety measures practice by medical laboratory workers in public hospitals of Dhaka city. Methodology: This descriptive cross-sectional study was conducted with Data from Medical Laboratory Workers of Tertiary Level Public Hospitals of Dhaka City using a Semi-Structured Questionnaire. The study was conducted from May 2015 to November 2015. It was designed to assess the Status of Practicing Biosafety Safety Measures in Tertiary Level Public Hospitals of Dhaka City. The knowledge, training, level of education on Biosafety were assessed by medical laboratory workers. Result: The Data of this study is obtained from a total of 238 respondents. In this study it is observed that 224(94\%) respondents could not say the concept of Biosafety as defined by WHO. In this study $118(49 \%)$ respondents do not know about biosafety cabinet and 84(35\%) could say up to Biosafety Level IV and $36(15 \%)$ can say up to Biosafety Level 3. Orientation with biosafety tools is observed in 138(58\%) respondents, 76(32\%) got training during course and 78(33\%) got training during service. Conclusion: In conclusion knowledge and training on biosafety of the laboratory worker are inadequate. [Bangladesh Journal of Infectious Diseases, December 2020;7(2):49-56]

Keywords: Knowledge; biosafety measures; laboratory personnel

Correspondence: Prof. Md. Nowfel Islam, Professor \& Head, Department of Neuropathology, National Institute of Neurosciences \& Hospital, Sher-E-Nagar, Agargaon, Dhaka, Bangladesh; Email: nowfel2008@gmail.com; Cell no.: $+8801552365185$

Conflict of interest: Authors have declared that there is no financial or other conflict of interests.

Funding agency: The study was not funded by any authority.

Contribution to authors: Islam MN, Kabir MH involved in protocol preparation, data collection and literature search up to manuscript writing. Yusuf MA, Salam MB, Perveen I, Shirin S involved in literature search, preparation and revision of this manuscript.

How to cite this article: Islam MN, Kabir MH, Yusuf MA, Salam MB, Perveen I, Shirin S. Knowledge of Biosafety Measures among Laboratory Personnel at Tertiary Level Public Hospitals in Dhaka City. Bangladesh J Infect Dis 2020;7(2):49-56

Copyright: ( 2020 . Islam et al. Published by Bangladesh Journal of Infectious Diseases. This article is published under the Creative Commons CC BY-NC License (https://creativecommons.org/licenses/by-nc/4.0/). This license permits use, distribution and reproduction in any medium, provided the original work is properly cited, and is not used for commercial purposes.
\end{abstract}




\section{Introduction}

Health care workers (HCWs) are at increased risk of occupational hazards as they perform their clinical activities in the hospital. They are exposed to blood borne infections by pathogens such as HIV, hepatitis B and hepatitis C, from sharps injuries and contacts with deep body fluids ${ }^{1-3}$. A number of micro-organism like bacteria, virus, and fungi may cause infection. The organism may be transmitted through different routes depending on particular type of pathogen. These may cause blood borne infection, droplet infection, air borne infection and contact transmission. More than one route may be used by some organisms ${ }^{4-6}$ Breathing, coughing, sneezing, talking; laughing of pathogen carrying patient may produce droplet or air borne particles. As these organisms can get access through the respiratory tract of the exposed individuals, so 'the use of respiratory and facial protection as well as other control measures taken by healthcare workers may reduce the risk of infection transmissions ${ }^{7}$.

Laboratory biosafety describes the containment, principles, technologies and practices that are implemented to prevent the unintentional exposure to pathogens and toxins, or their accidental release ${ }^{8}$. It is described as a safe method for managing infectious agents in laboratory environment where they are handled and maintained ${ }^{9}$. Implementation of Biosafety precautions decreases the exposure to the risk factors inside the laboratory. There are four main Biosafety levels for laboratories designated as; level-1 basic, level-2 containment, level-3 and maximum containment is level- $4^{10}$. Diagnostic laboratories located in public health centers, clinics and hospital, institutions and dealing with infectious materials are considered as a high risk area for staff working in it. Standards precautions such as gloves wearing, hands washing, safety glasses and face shield are highly recommended in diagnostic laboratories.

Regarding the laboratory biosafety the vision of WHO is 'Safe and secure environments in and around every laboratory in the world" ${ }^{\prime 1}$. In this regard the missions are to Lead, participate and collaborate in advancing Biorisk management, including biosafety and laboratory Biosecurity, to provide frame works, expertise and tools to inform, guide, and support WHO's member states in protecting the health of people in and around laboratory environments through appropriate Biorisk management, to establish a positive and growing culture towards responsible Biorisk management worldwide ${ }^{12}$.
Bangladesh has a very good health infrastructure. Both public and private health sectors are developing rapidly. There are 3197 registered private hospital in Bangladesh and in Dhaka city it is 747 in number. A total 14 large specialized hospital are available in Dhaka city and five large specialized hospitals are working outside Dhaka. There are 18 small specialized hospitals, 21 Govt. Medical colleges, 64 district hospitals are available in Bangladesh. All of these hospitals are tertiary level hospitals or referral hospitals. The military department has separate hospitals both at secondary and tertiary levels. All of the hospitals have diagnostic laboratories. As isolated diagnostic establishment there are 6422 private registered laboratories in Bangladesh and only in Dhaka city it is 1178 in number ${ }^{13}$. In addition, there is a Medical university having all diagnostic establishment as separate department, Diabetic hospital with the name as BIRDEM and its different branches, laboratory of public health department and an international research laboratory named ICDDRB and its branches.

There should study to evaluate the practicing Biosafety measures in diagnostic laboratories of our country. Also investigation on prevailing techniques, knowledge stillness and attitude of the laboratory worked should be measured and approach of practiced by diagnostic laboratories workers should be studied. Determination of knowledge of laboratory staff towards potential hazards should be searched out to adopt appropriate Biosafety policy. The purpose of the present study was to assess the Status of biosafety safety measures practice by medical laboratory workers in public hospitals of Dhaka city.

\section{Methodology}

This was a descriptive observational cross sectional study. The study was conducted from May 2015 to November 2015. A purposive sampling was done in this study. The respondents are the Laboratory Workers of Tertiary Level Public Medical Hospital of Dhaka City. The list of laboratories was collected from website of DGHS. There are 20 public tertiary level hospitals in Dhaka City. From the attendant registrar of those hospitals it is found that there are a total of 618 medical Laboratory Workers working currently in 20 public Tertiary Level Public Hospitals in Dhaka Metropolitan City. The list of hospitals was collected from web site of DGHS. The investigator himself went to the laboratories during office hour, moved desk to desk and office to office, request them, distributes the questionnaire, clears their asking and collected the 
data from the Laboratory Workers. Workers of all level including Pathologist, Laboratory Manager, Technologist, Sample Processor (Technician), Sample Collector (Phlebotomist) and cleaning staff available at the time of data collection were included in the study. Data collection was possible from a total of 240 respondents. A semi structured questionnaire was used. It contained closed type question, MCQ and open questions. The questionnaire also included the Introduction part, Written Consent part of the respondent and name and signature. The questionnaire was both in Bangla and in English. It was used on the demand of the respondents. Before starting the survey the questionnaire was pretested, finalized and piloting was done in one of the Laboratory for evaluation. The data was collected by the investigator himself.

\section{Result}

A total of 238 laboratory workers are included in this study.

General knowledge on Biosafety: "What is biosafety' was the question to the respondent. Out of 238 respondents, 58(24.0\%) respondents said it as 'the procedure to keep the Laboratory germ free', $8(3.0 \%)$ respondents said it as 'the activity to reduce health risk of the working people', $2(1 \%)$ of the worker said it as 'the principle of laboratory

Table 1: Distribution of Respondents by General Knowledge on Biosafety

\begin{tabular}{|l|c|c|}
\hline $\begin{array}{l}\text { Statement on } \\
\text { Biosafety }\end{array}$ & Frequency & Percent \\
\hline $\begin{array}{l}\text { Procedure to keep } \\
\text { Laboratory Germ Free }\end{array}$ & 58 & 24.0 \\
\hline $\begin{array}{l}\text { Activity to Reduce } \\
\text { Health Risk of the } \\
\text { Working People }\end{array}$ & 8 & 3.0 \\
\hline $\begin{array}{l}\text { Rule of Laboratory } \\
\text { Waste Management }\end{array}$ & 2 & 1.0 \\
\hline $\begin{array}{l}\text { Laboratory Specimen } \\
\text { Proper disposal Safety }\end{array}$ & 2 & 1.0 \\
\hline $\begin{array}{l}\text { Laboratory } \\
\text { alertness }\end{array}$ & 26 & 11.0 \\
\hline Personal protection & 18 & 8.0 \\
\hline $\begin{array}{l}\text { Maintenance of safe } \\
\text { laboratory } \\
\text { environment }\end{array}$ & 98 & 41.0 \\
\hline $\begin{array}{l}\text { Near to definition of } \\
\text { Biosafety }\end{array}$ & 14 & $\mathbf{1 0 0 . 0}$ \\
\hline No answer & & \\
\hline Total & & \\
\hline
\end{tabular}

waste management' and 2(1.0\%) respondents said it as 'the principle of waste management' $2(1.00 \%)$ respondents said it as proper disposal of laboratory specimen. $12(5.0 \%)$ respondents said it as safety alertness in a laboratory. 26(11.0\%) respondents said it as personal protection. 14(6.0\%) respondents said it as biosafety is the principles, technologies and practices that are implemented to prevent the unintentional exposure to pathogens and toxins, other hazardous substances including accidents. 98(41.0\%) of the respondent did not answered (Table 1).

Knowledge on Need of Biosafety: The laboratory workers were asked about the 'Need' of Biosafety Measures. Out of 238 respondent 48(20\%) answered that it is needed 'to protect the worker from infection', $12(5 \%)$ respondents answered that it is needed 'to produce good laboratory report', 32(13) respondents answered that it is needed 'to reduce health risk of medical laboratory worker', 44(19) respondents answered that it is needed 'to secure worker from life threatening infection' and $10(4 \%)$ said to prevent biohazard', 92(39\%) laboratory workers did not responded on this question. The answers are presented in the table below (Table 2).

Table 2: Distribution of Respondents by Knowledge on Need of Biosafety

\begin{tabular}{|l|c|c|}
\hline $\begin{array}{l}\text { Statement on the } \\
\text { Need of Biosafety }\end{array}$ & Frequency & Percent \\
\hline $\begin{array}{l}\text { To Protect Workers } \\
\text { From Infection }\end{array}$ & 48 & 20.0 \\
\hline $\begin{array}{l}\text { To Produce Good } \\
\text { Report }\end{array}$ & 12 & 5.0 \\
\hline $\begin{array}{l}\text { To Reduce Health } \\
\text { Risk }\end{array}$ & 32 & 13.0 \\
\hline $\begin{array}{l}\text { To secure from Life } \\
\text { Threatening Infection }\end{array}$ & 44 & 19.0 \\
\hline To prevent biohazard & 10 & 4.0 \\
\hline No response & 92 & 39.0 \\
\hline Total & $\mathbf{2 3 8}$ & $\mathbf{1 0 0 . 0}$ \\
\hline
\end{tabular}

Knowledge on Biosafety Cabinet and Biosafety Level: Biosafety cabinet is used as one of the important biosafety devices. Knowledge on level of biosafety and biosafety cabinet are important in biosafety management. On searching the knowledge on biosafety cabinet and biosafety level it is observed that 118 laboratory workers do not know about biosafety cabinet. Among rest of the respondents, $84(35 \%)$ respondents could say up to level IV, but $36(15 \%)$ respondent described up to level 3 (Table 3). 
Table 3: Distribution of Respondents by Knowledge on Biosafety Cabinet and Biosafety Level

\begin{tabular}{|l|c|c|}
\hline Biosafety Level & Frequency & Percent \\
\hline Level I & 00 & 0.0 \\
\hline Level II & 00 & 0.0 \\
\hline Level III & 36 & 15.0 \\
\hline Level IV & 84 & 35.0 \\
\hline No answer & 118 & 50.0 \\
\hline Total & $\mathbf{2 3 8}$ & $\mathbf{1 0 0 . 0}$ \\
\hline
\end{tabular}

Knowledge on Biosafety Assurance: Biosafety assurance is important issue that may reduce the health risk of laboratory workers. This study tried to ascertain the understanding of the laboratory worker 'How the Biosafety can be 'assured' in our sating. $106(45 \%)$ of the respondents did not report on this question. 32(13\%) respondents said it as 'By following biosafety rule', $04(2 \%)$ respondent said 'By creating awareness', 4 (2\%) responder said it as 'By regular supply of PPE and biosafety tools', responded it as By providing training on biosafety', $12(5 \%)$ said it as 'By Regular supervision', 10(4\%) said it as 'By the involvement of the government', $30(12 \%)$ respondents said it as 'By combined effort' and 28 (11) respondents said it as 'By using safety cabinet' (Table 4).

Table 4: Distribution of the Respondents by Knowledge on Biosafety Assurance

\begin{tabular}{|l|c|c|}
\hline Text of Answer & Frequency & Percent \\
\hline $\begin{array}{l}\text { Following Biosafety } \\
\text { Rule }\end{array}$ & 32 & 13 \\
\hline Creating Awareness & 04 & 2 \\
\hline $\begin{array}{l}\text { Regular Supply Of PPE } \\
\text { And Biosafety Tools }\end{array}$ & 04 & 2 \\
\hline $\begin{array}{l}\text { Providing Training on } \\
\text { Biosafety }\end{array}$ & 12 & 5 \\
\hline Regular Supervision & 12 & 5 \\
\hline $\begin{array}{l}\text { Involvement Of The } \\
\text { Government }\end{array}$ & 10 & 4 \\
\hline $\begin{array}{l}\text { Combined Effort } \\
\text { Using Safety Cabinet }\end{array}$ & 28 & 12 \\
\hline No Answer & 106 & 45 \\
\hline
\end{tabular}

Knowledge on Hazard due to Lack of Biosafety Measure: Lack of biosafety measures may create hazard at different areas of our life and environment. Understanding of Medical laboratory Workers on this area was searched out in this study. Out of 238 respondents, 102(43.0\%) respondents said that 'Lack of biosafety measures creates risk of environmental pollution', 106(45.0\%) respondents answered that 'It creates occupational health hazard', $118(50.0 \%)$ respondents said that 'It create public health hazard. However, 10(4.0\%) respondents said that 'There is no hazard at all' (Table 5).

Table 5: Distribution of Respondents by Knowledge on Hazard Due To Poor Biosafety

\begin{tabular}{|c|c|c|}
\hline Text of Answer & Frequency & Percent \\
\hline $\begin{array}{ll}\text { Environ } & \text { mental } \\
\text { pollution } & \end{array}$ & 102 & 43.0 \\
\hline $\begin{array}{l}\text { Occupational health } \\
\text { hazard }\end{array}$ & 106 & 45.0 \\
\hline $\begin{array}{l}\text { Create public health } \\
\text { hazard }\end{array}$ & 118 & 50.0 \\
\hline $\begin{array}{l}\text { There are no hazard at } \\
\text { all }\end{array}$ & 10 & 4.0 \\
\hline
\end{tabular}

Knowledge on responsibility for Biosafety: Without responsibility no program can be executed. For Biosafety Measure someone should be assigned. 'Who may be the responsible person Biosafety' was under investigation. Sixteen (7\%) respondents said that 'It is the responsibility of all', 98(41\%) said that 'It is individual responsibility', 116 (49\%) said It is Laboratory Author's responsibility and $85(36 \%)$ said that 'It is Government's responsibility' (Table 6).

Table 6: Distribution of Respondents by Knowledge on Responsibility of Biosafety Assurance

\begin{tabular}{|l|c|c|}
\hline $\begin{array}{l}\text { Presume } \\
\text { Responsibility }\end{array}$ & Frequency & Percent \\
\hline Responsibility of All & 16 & 7 \\
\hline $\begin{array}{l}\text { Individual } \\
\text { responsibility }\end{array}$ & 98 & 41 \\
\hline $\begin{array}{l}\text { Laboratory Authorities } \\
\text { responsibility }\end{array}$ & 116 & 49 \\
\hline $\begin{array}{l}\text { The Government's } \\
\text { responsibility }\end{array}$ & 85 & 36 \\
\hline
\end{tabular}

Knowledge on Impact of Biosafety Measure: This study also investigated the knowledge of the respondents on Impact of practice of Biosafety Measures' through MCQ. Practice of Biosafety Measures 'Improve the Laboratory Services' was answered by $84(35 \%)$ and not answered by $154(65 \%)$ respondent. Practice of Biosafety measures 'Reduce the Health Risk of the worker', was answered by 134(56\%) and not answered by 104(44\%) respondent. Practice of Biosafety Measures 'Facilitate the TQM' was answered by $106(45 \%)$ respondent and not answered by 132 (55\%) respondent. Practice of Biosafety Measures 
'Influence Geno preservation' was answered by 52 (22\%) respondent and not answered by $186(78 \%)$ respondents (Table 7).

Table 7: Distribution of Respondents by Knowledge on Impact of Biosafety Measure

\begin{tabular}{|l|c|c|}
\hline Expected outcome & Frequency & Percent \\
\hline $\begin{array}{l}\text { Improve the laboratory } \\
\text { services }\end{array}$ & 84 & 35 \\
\hline $\begin{array}{l}\text { Reduce the Health } \\
\text { Risk of the workers }\end{array}$ & 134 & 56 \\
\hline Facilitate the TQM & 106 & 45 \\
\hline $\begin{array}{l}\text { Influence Geno } \\
\text { preservation }\end{array}$ & 52 & 22 \\
\hline
\end{tabular}

\section{Discussion}

Biosafety is the principles, technologies and practices that are implemented to prevent the unintentional exposure to pathogens and toxins, other hazardous substances including accidents. The current study is a descriptive cross sectional observational study. The study is conducted to investigate the knowledge about the Biosafety Measures of Medical Laboratory Workers of Tertiary Level Public Hospitals of Dhaka City. It is expected that all the laboratory manager and technologist in public level should be with medical background. In this study we observed that there are some workers who are not with medical background. Probably this is due to procedure of promotion. In the past, due to lack of adequate diploma technologists, those works were done by workers other than diploma holders. Now a day it is not happening.

The current study inquired about the general knowledge on Biosafety, Need of Biosafety Measures, Knowledge on Biosafety Cabinet and Technique for Biosafety Assurance. A large amount of scientific knowledge and data has a direct impact on biosafety, and it can be a difficult process to collect this information in a credible way in order to create a balanced view ${ }^{10}$. In this study we found that only $14(6 \%)$ respondent can say at least the concept of laboratory biosafety properly as defined and $94 \%$ could not say it. This observation clearly says existing very poor status on Knowledge on Biosafety.

Wader et $\mathrm{al}^{13}$ reported in their work on knowledge on biosafety measures of knowledge of biosafety. They reported that $50 \%$ of pathology technicians had good score on knowledge on biosafety. On the other hand, $25.0 \%$ of biochemistry technician had average knowledge, $75.0 \%$ had good knowledge. They also found that $100 \%$ technician of microbiology had good score on knowledge on biosafety.

The knowledge on regulations of the Clinical Laboratory Science Educators of Square University of Saudi Arabia was studied by Cruz et $\mathrm{al}^{15}$ They reported that the knowledge of Clinical Laboratory Science Educators of the University is moderate but they enumerate gaps that need to be addressed such as lack of biosafety trainings and seminars, existence of laboratory acquired infection, and poor dissemination of national and institutional safety regulations. In terms of biosafety specific knowledge, the need to improve their knowledge on several aspects like the use of a biosafety manual, responsibility for the adherence to biosafety regulations, personal protective equipment, biosafety containment level, and protection in the daily laboratory work. Recommended measures are suggested to address the identified gaps, which include behavioral based biosafety training, one or two short talks or seminars, and revision of institutional safety guidelines.

'What is biosafety' was the question to the respondent. Out of 238 respondent, 58 (24.4\%) respondent answered it as 'the procedure to keep the Laboratory germ free', $8(3.4 \%)$ said it as 'the activity to reduce health risk of the working people'. $2(0.8 \%)$ of the worker said it as 'the principle of laboratory waste management' and $2(.08 \%)$ said it as proper disposal of laboratory specimen. $12(5 \%)$ said it as safety alertness in a laboratory, 26(10.9) said it as personal protection. $14(6 \%)$ said it as biosafety is the principles, technologies and practices that are implemented to prevent the unintentional exposure to pathogens and toxins, other hazardous substances including accidents. 98(41.2\%) respondent did not answered. Most of this answer is parts of the knowledge on biosafety. Only $6 \%$ could say the proposed concept of WHO. It reflects the status poor knowledge of the laboratory workers of the study population.

In the present study the Laboratory Workers were asked about the 'Need' of Biosafety Measures. Out of 238 respondents, 48(20.2\%) answered it also protect the worker from infection, 12(5\%) answered it as to produce good laboratory report, 32(13.4\%) answered it as to reduce health risk of medical laboratory worker, 44(18.5) to secure worker from life threatening infection and 10(4.2\%) answered it as to prevent biohazard. Ninety two $(38.7 \%)$ of the respondents did not answer to this question. 
WHO describe the Biosafety measures as containment of Biohazards, Methods and Practice for the safe handling of pathogenic microorganisms in laboratories within their geographical borders, safe use of recombinant DNA technology and transport of infectious materials, personal protection $^{11-16}$. Biosafety regulation is key to ensuring the environmental and human safety of GMOs and giving the public confidence in GMO products $^{11}$.

Sreedharan et $\mathrm{a}^{15}$ reported that among their $98 \%$ knew that the ideal method of disposal of sharp waste was to put it in a puncture proof container immediately after use. $93.1 \%$ of the nurses reported that the needle pricks, cuts or scratches should be bled by squeezing. 93\% habitually used masks always during surgery and $80.4 \%$ always wore goggles during surgery. With regard to recapping of needles, $44.6 \%$ were aware that needles should be recapped by single hand technique after use and among them $93.3 \%$ practiced this method; there was a statistically significant association $(p<0.001)$ between the awareness and practice, but not between years of experience and needle recapping technique after use. The knowledge among nurses about preventive measures in occupational exposure to blood and body fluids is adequate but in practice it is inadequate. In this study we observed that only $12.5 \%$ respondent answered as to produce good laboratory report. That is $87.5 \%$ respondent feel the need of biosafety measures but could not express the need. It reflect a poor communication skill of the workers.

Biosafety cabinet is used as one of the important Biosafety devices. Knowledge on level of biosafety and biosafety cabinet are important in Biosafety Management. On searching the knowledge on biosafety cabinet and biosafety level in this study it is observed that $118(50 \%)$ laboratory workers do not know about biosafety cabinet. Among the other respondents, 84 (35\%) could say up to level 4 but $36(15 \%)$ respondent described up to level 3. Diagnostic laboratories located in public health centers, clinics and hospital, institutions and dealing with infectious materials are considered as a high risk area for staff working in it ${ }^{12}$. Biosafety cabinet is used to maintain the Biosafety levels. There are four main Biosafety levels for laboratories designated as; level-1 basic, level-2 containment, level-3 and maximum containment is level- $4^{11}$. In this study only about $50 \%$ of the respondent could respond on the question. Clearly it indicates status of poor knowledge on biosafety cabinet thus knowledge on Biosafety Level. The study conducted by Eduma ${ }^{17}$ on biosafety was published in the year 2012. They found biosafety cabinet in $11(6 \%)$ laboratories, autoclave in $28(15 \%)$ and incinerator in only two (1\%) laboratories. In this study we found three biosafety cabinets in six institutions out of twenty. Also it is a poor index of practice of Biosafety measures.

Biosafety Assurance is important in reducing health risk of laboratory workers. Current study tried to ascertain the knowledge of the worker 'how the Biosafety can be assured.' Out of 238, 106 (45\%) of the respondents did not report on this question. that indicate that they do not know it. On the other hand $55 \%$ answered it in different approaches. These are 'following biosafety rule' 32 (13\%), 'By creating awareness' 4(2\%), 'By regular supply of PPE and biosafety tools' $4(2 \%)$, 'By providing training on Biosafety' 12 (5\%), 'By Regular supervision' 12 (5\%), 'By the involvement of the government' 10(4\%), 'By combined effort' and 'By using safety cabinet' 28(12\%).The University of Tennessee mitigates the inherent risks associated with the laboratory setting by seeking to build a culture of safe work practices at the university. To do so, they provide a variety of activities such as organizing an Institutional Committee, development of policy and procedure for Biosafety, waste management and biological safety and training to those involved in the investigation of biological activities in the form of classroom and online training sessions as well as informational modules found in web site ${ }^{15}$. In the current study Institutions we did not observed such program.

The laboratory working people should know all of the stated activities. But in this study we found only $56.0 \%$ know few of the activity partially. This reflects the poor knowledge on the issue among the laboratory workers. None of the Institutions have any committee and policy for Biosafety measures to be executed. Lack of Biosafety measures may create hazard at different affected areas. Knowledge on the hazards areas were searched out in the current study. Only 10 (4\%) working people said that it creates no hazard. Rest of $96 \%$ respondents informed that the hazardous areas are 'Environment' (43\%), 'Occupational Health' (45\%) and 'Public Health' (50\%). Uniformity of the response was expected. The variation on the response may be due to heterogeneous study population with heterogeneous level of education ${ }^{14}$.

Without responsibility no program can be executed properly. For Biosafety someone should be responsible. 'Who is responsible for Biosafety activity' was search out in this study. Only 7\% said 'All concerned' are 'Responsibility for it. Rest of 
the opinions are 'Individual', Laboratory authority' and the Government's. Cruz et $\mathrm{al}^{14}$ had the same question in their study. They got the response as 'administrators (7\%), biosafety officer- (23\%), lab. Director (19\%), lab technicians $(3 \%)$ and everybody $(48 \%)$. The designation of the responsible persons are consistent with the current study and the study of Cruz et $\mathrm{al}^{14}$ but the percentage of the respondents varied, particularly in respect to 'Responsibility of All'. They found it $48 \%$ and the current study reveals it only $7 \%$. This variation may be due to variation in study setting and the target population with different level of education. The respondents were requested to express their experience related to Biosafety during their service life. Out of 238, $112(47 \%)$ did not noted any experience. Rest of the respondents reported on 'Accidents' (15\%), 'Comments on Biosafety' $28.6 \%$, passed suggestion $(6.7 \%)$ and 'Own limitation on Biosafety' (2.5\%).

The reported accidents are 'Acid burn of clothing' (3 cases), 'Acid burn of hand' (7 cases), Acid ingestion ( 2 cases), 'Fire burn's ( 2 cases), 'Cutting of foot by broken glass' (1 case), Chemical Ingestion during mouth pipetting' (1 case), 'Hand cutting during cleaning the glass slide and test tube' ( 5 cases), 'Fire in laboratory' ( 2 case), 'Acid flush of Eye' (1 case), 'Needle pricking's (Unknown patient) 3 cases, 'Needle pricking' (HBsAg +ve) 1 case, 'Tuberculosis' 3 cases, 'Chemical ulcer of hand' 2 cases, 'Electric burn' 1 case and 'Damage of Machine from over voltage' 1 case. But none of the laboratory maintain any accident record. Sreedharan et $\mathrm{al}^{15}$ reported $26.7 \%$ of the respondents had exposure to splashes of blood and body fluids into the eyes or mouth. Though the respondents reported on accidents they observe but also they reported that none of the laboratory has any accident registrar. The study of Nasim et al ${ }^{17}$ also reported that 83.4 of the study laboratory did not maintained accident record. The current study is consistent with the study in this regard. The similarity may be due to similar socio-educational status.

The respondents were requested to pass comments on practicing biosafety. 68 (29\%) of the respondent passed their comment on biosafety as they think. The comments are very important and the concern authority should consider those. "Poor Biosafety measures create occupation health hazard. So the worker should be trained". The comment "Issue of Biosafety is an important and neglected issue. Immediate step should be taken". Probably these are true. We are observing that the cleaning and disposal system of our social structure is not able to cope with the journey of science and technology as well as the changes in attitude and practice of consumption of Bio-products. The comments and suggestion such as "Biosafety is the heart of a laboratory. Worker should be trained properly so that they may remain free of disease and may have good output of report" and "Assurance of Biosafety in a running laboratory is essential." All of these are needful and scientific comments. The Authority may consider these during policy making. Many of the laboratories do not maintain Biosafety protocol due to lack of proper management and training. Also good management and supply can assure the Biosafety" these are very good explanation and suggestions. According to the comments only a few workers come to know about Biosafety in early period and early service. They comment that the management of Biosafety is authority's responsibility" should also be accepted. The comment "Both private and Public laboratory workers should know Biosafety measures" should also be considered by the policy makers because a large number of health coverage including diagnostic, therapeutic and preventive health services are provided by the private sectors.

The respondents were requested to pass suggestion and to express their limitation in the open section of the questionnaire. They suggested to 'Improvement the status of Biosafety Measures should be taken akin immediately to save the worker and the environment'. The respondents agreed their limitation on Biosafety by stating that they 'Do not have enough knowledge on Biosafety' and 'Trying to improve Biosafety level but do not get sufficient area/place to make standard laboratory'. These expressions are highly appreciable and reflect excellent good moral base of responding workers.

In current study it is observed that $138(58 \%)$ of the laboratory workers are oriented with Biosafety Tools and $100(42 \%)$ of the respondents are not oriented with Biosafety tools. The laboratory workers are mostly skill persons. So almost all of them should be oriented with biosafety tools. The poor status or partial lacking of orientation of all level laboratory workers at public health sector should be taken in consideration to improve the status of Biosafety in our country. Knowledge skill and attitude are three objectives of teaching. Without training skillfulness cannot develop. For practice of Biosafety, the medical laboratory workers must have training on Biosafety. In this study we observed that training on Biosafety is not uniform in terms of trainee, syllabus, timing and training providing authority. We observed that out of 238 respondents, $32 \%$ have training in their 
course and $68 \%$ do not. On the other hand $33 \%$ have training during service and $67 \%$ have no training during service life. DHG provided training only to 13 worker and $87 \%$ workers do not have any training from DGHS. Rest of the training was provided by the local laboratory authority by selfinitiative.

The local initiative is a positive attitude of the initiating laboratory authority. In respect to syllabus, we observed that 67 respondent did not have the topic in the syllabus. The more young workers have the topic in syllabus. Hopefully day by day more workers will be available with academic background. Aksoy et $\mathrm{al}^{18}$ reported in their study with $23.5 \%$ of the participants stated that they had previously taken education about biosafety $(\mathrm{p}=0.002)$.

Nasim et $\mathrm{al}^{17}$ reported that $85 \%$ of their respondents had no formal training on Biosafety. Only 5.2\% participants had training about response to fire emergency in the report of Eduma ${ }^{16}$. The observation of the current study is in agreement with that of Nasim et $\mathrm{al}^{17}$ observation. This similarity may be due to similar socio-demographic similarity. On the other hand $23.5 \%$ respondents who are trained in turkey is not that much. This little elevated value also may due to sociodemographic infrastructure.

\section{Conclusion}

This Dhaka City based cross sectional observational study conclude that knowledge and training on Biosafety of the Laboratory worker are inadequate. The Guide line needs incorporate of Biosafety as a topic in syllabus, training on Biosafety during course and in-service, motivational program, regular supply, adequate physical, financial and prophylactic support and regular supervision and upgrading the system of waste disposal. A broad spectrum survey may be carried out for further evaluation.

\section{References}

1. Gerbending JL. Incidence and prevalence of human immunodeficiency virus, hepatitis B virus, hepatitis $\mathrm{C}$ virus and cytomegalovirus amongst health care personnel at risk of blood exposure: final report from a longitudinal study. $\mathrm{J}$ infect Dis. $1994 ; 170: 1410-1517$
2. Ramos-Gomez F, Ellison J, Greenspan D, et al. Accidental exposure to blood and body fluids amongst health care workers in dental teaching clinics; a prospective study. J Am Dental Assoc. 1997; 1 28:1253-126

3. Reuben FL, Norden CW, Rockwell K, et al. Epidemiology of accidental needle puncture wounds in hospital workers. Am J Med Sci. 1983;286:26-30

4. Aids epidemic up date: December 2003. Geneva. Joint United Nations Program on HIV/AIDS and world health organization and UNAIDS/03.39E

5. Pruss-Ustun A, Rapiti E, Hutin Y. Sharps injuries: global burden of disease from sharps injuries to health-care workers. Geneva, Switzerland. World Health Organization, 2003

6. Orji EO, Fasubaa OB, Onwudiegwu U, et al. Occupational health hazards among health care workers In an Obstetric and Gynecological unit of a Nigerian Teaching hospital. J Obstra Gyneocol. 2002;22:75-7

7. World Health Organization. The word health report 2002: Reducing Risks, promoting health life. World Health Organization, Geneva

8. International Health Care Worker Safety center. Estimated Annual number of US Occupational Injuries and Mucocutaneous Exposures to Blood or Potentially Infective Biological Substances. Avd Exposure Prevent 1998; 4:3.

9. Biosafety in the Laboratory, Prudent Practices for the Handling and Disposal of Infectious Material. Washington, D.C. Pg: NRC, National Academy Press; 1989. Safe handling of infectious agents; pp. 13-33.

10. Gershon RR, Karkashian CD, Vlahov D, Kummer L, Kasting C, Green-McKenzie J, et al. Compliance with universal precautions in correctional health care facilities. Journal of Occupational and Environmental Medicine. 1999;41(3):181-9.

11. Center for Dosease Control and Prevention. Work Place safety and Health Topic. Skin exposure and effect. 1600 Clifton Rd. GA30329-4027, USA 800-CDC -INFO 800-232-4636) TTY: (888) 232-6348.

12. Boyce JM, Pottet D. Guide line for hand washing for health care setting: Recommendation for the healthcare infection control practice Advisory Committee and HICPAC/SHEA/IDSA Hand hygiene work force. MMWR Morb Mortal Wkly Res 2002; 51:-44.

13. Wader JV, Kumer V, Mutalik AV. Knowledge , Attitude, Practice of Biochemistry among laboratory technician in a teaching hospital. IJHSR. 2013;3(6):28-33.

14. Cruz CP, Abu Bakr ESA, Thazha SK, et. al. Biosafety knowledge and perceptions of clinical laboratory science educators in a Saudi university Int J Health Sci Res 2015;5(6): 196-204

15. Sreedharan J, Muttappallymyalil J, Venkatramana M. Knowledge and practice of standard measures in occupational exposure to blood and body fluids among nurses in a University Hospital in the United Arab Emirates. Italian Journal of Public Health. 2010;7(1):90-94

16. Eduma AH. Assessment of biosafety precautions in Khartoum state diagnostic laboratories Sudan. Pan Aft Med J 2012;11:19:1-5

17. Nasim S, Shahid A, Mustufa MA, Kazmi SU, Siddiqui TR, Mohiuddin S, et al. Practices and awareness regarding biosafety measures among laboratory technicians working in clinical laboratories in Karachi, Pakistan. Applied Biosafety. 2010;15(4):172-9

18. Aksoy U, Ozdemir MH, Usluca S. Toprak Ergonen A. Biosafety profile of laboratory workers at three education hospitals in Izmir, Turkey. Microbiol Bul. 2008; 42(3):469-76 